9 Selbst SM, De Maio JG, Boenning D. Mouth wash poisoning. Clin Pediatr 1985;24:162-3.

10 Wright J. Ethanol-induced hypoglycaemia. Br J Alcohol Alcoholism 1979;14:174-6.

11 Ricci LR, Hoffman S. Ethanol induced hypoglycaemic coma in a child. Ann Emerg Med 1982;1 1:203-4.

12 Gershman H, Steeper J. Rate of clearance of ethanol from the blood of intoxicated patients in the emergency departthe blood of intoxicated patients in the
ment. J Emerg Med 1991;9:307-11.
13 Simon HK, Cox JM, Sucov A, Linakis JG. Ethanol clearance in intoxicated children and adolescents presenting to the ED. Acad Emerg Med 1994;1:520-4.

14 Gibson PJ, Cant AJ, Mant TGK. Ethanol poisoning. Acta Paediatr Scand 1985;74:977-8.

15 Pollack CV, Jorden RC, Carlton FB, Baker ML. Gastric emptying in the acutely inebriated patient. J Emerg Med emptying in the

See also letters on p00

\title{
CS gas exposure in a crowded night club: the consequences for an accident and emergency department
}

\author{
A Breakell, G G Bodiwala
}

\begin{abstract}
A case is reported of deliberate release of CS gas (O-chlorobenzylidene malononitrile) in an enclosed space and the consequences for an accident and emergency department.

(F Accid Emerg Med 1998;15:56-64)
\end{abstract}

Keywords: CS gas

\section{Case report}

Twenty three people (eight males, 15 females) attended the accident and emergency (A\&E) department at the Leicester Royal Infirmary following exposure to $\mathrm{CS}$ gas (O-chlorobenzylidene malononitrile) in a local night club. The average age of the males was 22 years and of the females, 21 . There were two known asthmatics in the group. The patients attended the A\&E department approximately $20 \mathrm{~min}$ utes after exposure to the CS gas and were in contact with the gas for 10 to 15 minutes while in the night club.

\section{TRIAGE}

On arrival at the $A \& E$ department, individuals were assessed at triage by an experienced nurse. Their clothes were removed and placed in plastic bags. Patients were triaged into two areas. The recovery ward of the A\&E department received those patients with minor symptoms and the windows were opened for ventilation. Patients with difficulty in breathing, chest tightness, and choking sensation also

Accident and

Emergency

Department, Leicester

Royal Infirmary,

Leicester, UK

A Breakell

G G Bodiwala

Correspondence to: Dr A Breakell, Accident and Emergency Department, Royal Liverpool University Hospital, Prescot Street, Liverpool L7 8XT, UK.

Accepted for publication 29 September 1997 had severe eye symptoms and were seen in the resuscitation room.

\section{CLINICAL ASSESSMENT}

Twelve of the 23 patients who attended the department discharged themselves before being seen by the doctor but had been assessed by a senior nurse on the recovery ward. Patients seen in the resuscitation room had eye and breathing problems. Irritation to the eyes was initially treated by blowing cold air from an electric fan onto the face. ${ }^{1}$ Six patients had eye irrigation with normal saline with considerable improvement in symptoms. Of those with respiratory problems, seven required supplemental oxygen. Two of these patients suffered from asthma. Clinically none of the patients developed wheeze but one asthmatic patient required a nebuliser for chest tightness. One patient was admitted to hospital with persistent chest tightness and sore throat. $\mathrm{He}$ was discharged after 24 hours with resolution of his chest tightness, but the sore throat persisted.

\section{Discussion}

While CS gas attacks are rare in this country at present, increasing availability of this substance at home and across Europe is likely to increase "the practical joke" and more serious cases of chemical terrorism and criminal attacks. The National Poisons Information Service (London) is currently attempting to monitor the number of incidents involving CS gas. ${ }^{2} \mathrm{At}$ present it is one of three agents used in crowd control, the others being 1-chloroacetophenone (CN gas) and dibenzoxazepine (CR gas). The use of $\mathrm{CN}$ and $\mathrm{CR}$ has decreased because of their toxic effects. Although called "gas," the chemicals are solids and are used in powder form. They are sprayed from liquid aerosols for convenience. The most toxic of these agents is CN gas which is a constituent of Mace, the self defence spray, and deaths from pulmonary injury and asphyxia have been reported; $\mathrm{CN}$ gas is also capable of causing serious damage to the eyes. ${ }^{3} \mathrm{CR}$ gas is the most potent lacrimator but has the least systemic effects. CS gas is a potent lacrimator and is the least toxic of the chemical compounds.

The effects of exposure to CS gas vary depending upon the concentration to which the person is exposed. On exposure even to low concentrations, the onset of symptoms is immediate. The effects usually settle within 15 to 30 minutes after removal from exposure. Eye, nose, mouth, respiratory tract, and skin symptoms predominate. ${ }^{4}$ Lacrimation, pain, blepharospasm, conjunctival erythema, and periorbital oedema develop, along with pain and discomfort in the nose, a burning sensation in the mouth, nausea and rarely vomiting, and respiratory symptoms of sore throat, tight chest, 
coughing, bronchospasm, and occasionally laryngospasm. There is no evidence that patients who suffer from pre-existing lung disease (for example, asthma or chronic bronchitis) are at increased risk of an exacerbation. ${ }^{3}$ On contact with the skin a burning sensation and erythema occurs, which settles in 24 hours. Prolonged exposure and wet clothing can result in a chemical burn. CR gas can affect the skin upon contact with water 24 hours later. $\mathrm{CN}$ gas is a skin sensitiser and can produce allergic contact dermatitis within 72 hours of exposure. ${ }^{5}$ Allergic contact dermatitis has been reported following exposure to $\mathrm{CS}$ gas.

RECOMMENDED AFTERCARE OF SUBJECTS WHO HAVE BEEN EXPOSED TO CS GAS

In the majority of cases the effects resolve spontaneously within 15 to 30 minutes once the person is removed from the contaminated area and exposed to cool fresh air. This will permit CS particles to be blown off the body. Studies by the military endorse these first aid measures. ${ }^{6}$ Clothing should be removed and sealed in plastic bags and patients should be placed in a well ventilated area. They should be advised not to rub their face or eyes as this increases the effects of the CS. The face should be wiped with gauze, particularly the thin skin around the eyes, to remove CS particles before washing the face. Patients with respiratory symptoms should be admitted for observation. Humidified oxygen provides symptomatic relief. Following eye exposure, natural tear secretions are normally sufficient to remove the chemical from the eye, but where ocular effects persist the National Poisons Information Service (London) recommends eye irrigation using saline or water, and the information given to police forces around the United Kingdom suggests the "use of copious amounts of cool tap water to flush CS from the face and eyes." It has been reported ${ }^{1}$ that blowing air directly onto the eye with an electric fan is the preferred treatment following persistent irritation to the eyes, but it is difficult to see how a powder that dissolves in solution on the surface of the eye can be converted into a gas at normal temperature and pressure and relieve irritation. $\mathrm{CN}$ gas being a constituent of Mace and a severe eye irritant, others have recommended saline irrigation. ${ }^{7}$ Subjects who have been sprayed should be asked if they wear contact lenses. People wearing contact lenses may experience greater discomfort, and these should be removed immediately. Exposure to CS gas, in common with other substances-for example, the solvent methyl iso-butyl ketone currently on trial with some police forces in the United Kingdom-may cause damage to certain types of lens.

Following exposure to the skin, washing with soap and water normally settles the burning sensation. Any chemical burns should be treated as thermal burns, and topical steroids may be used for contact dermatitis.

\section{Lessons from our experience}

(1) Expect large numbers of patients when exposure to CS gas occurs in closed spaces. The problems of exposure in closed spaces have been addressed ${ }^{3}$ and the indications are that an exposure of $6000 \mathrm{mg} / \mathrm{min} / \mathrm{m}^{3}$ would encroach on the margin of safety but would still be several times less than the level at which fatalities might occur providing the subject is healthy and can escape.

(2) Triage to separate the mild from the moderate and severe exposure. Mild symptoms involve irritation to the mucous membranes; severe symptoms represent an exaggeration of these. Remember that panic and hysteria can superven $e^{4}$ but be vigilant when dealing with patients with eye and respiratory complications.

(3) If eye symptoms persist for longer than 30 minutes after exposure we recommend irrigation of the eyes using normal saline, followed by visual acuity testing. If problems persist the patient should be referred to an ophthalmologist. Blowing cold air onto the face did not result in clinical improvement. The electric fan distributed CS particles from the patients' skin and hair and increased contamination of the resuscitation room.

(4) In accordance with findings from Londonderry, ${ }^{3}$ our patients with asthma were no more sensitive to CS gas than the normal individuals, though reports from unclassified information on the use of CS gas in Seoul, South Korea, ${ }^{8}$ claim that a deterioration in lung function occurs in patients with asthma and chronic obstructive lung disease. Our only admission was a previously healthy man with persistent sore throat and chest tightness unrelieved by oxygen. Peak flow values were unchanged between admission and discharge in patients with respiratory symptoms.

(5) Educate $A \& E$ staff in dealing with chemical attacks from crowd control agents.

1 Yih JP. CS gas injury to the eye. BMJ 1995;311:276.

Wheeler H, Murray V. Treating CS gas injuries to the eye. Poisons centre will monitor cases. BMJ 1995;311:871.

3 Himsworth H, Black DAK, Crawford T, Dornhorst AC Gilson JC, Neuberger A, et al. Report of the enquiry into the medical and toxicological aspects of CS. London: HMSO, 1971.

4 Beswick FW. Chemical agents used in riot control and warfare. Hum Toxicol 1983;2:247-56.

5 Leenutaphong V, Goerz G. Allergic contact dermatitis from chloroacetophenone (tear gas). Contact Dermatitis 1989; 20:316.

6 Punte CL, Owens E, Gutentag PJ. Exposures to orthochlorobenzylidene malononitrile. Arch Environ Health 1963;6:366-74.

7 Scott RA. Treating CS gas injuries to the eye. Illegal "Mace" contains more toxic CN particles. BMJ 1995;311:871.

$8 \mathrm{Hu} \mathrm{H}$, Fine J, Epstein P, Kelsey K, Reynolds P, Walker B Tear gas-harassing agent or toxic chemical weapon? JAMA 1989;262:660-3. 